\title{
Advanced High-Gain Slot Antenna Arrays for 5G and Radar Applications
}

\author{
Marija Milijic, Member, IEEE, and Branka Jokanovic, Senior Member, IEEE
}

\begin{abstract}
This paper presents an advanced design of highgain slot antenna array at $\mathrm{K}$-band using slots as radiating elements serially fed by coplanar waveguide $(\mathrm{CPW})$. The arrays consist of identical slots of rectangular shape positioned symmetrically relative to the CPW feeding line. Firstly, the linear arrays of 14 slots are examined considering mainly their bandwidth and radiation characteristics. In addition, two identical linear sub - arrays of 14 slots are investigated when they have separate feeding in the form of two generators for each sub - array. Last, a CPW T-junction is employed to feed the antenna consisting of $2 \times 14$ slots which resulted in a wide operating bandwidth and maximum gain of $21.0 \mathrm{dBi}$ which proved to be $2.25 \mathrm{~dB}$ less gain than with independent feeding. In order to enhance the antenna gain, both arrays are terminated with open-circuited stubs, so that the energy remaining after the last array element is reflected from the stub and re-radiated through the slot arrays. The length of the stubs is optimized to provide that the reflected wave is in phase with the forward-traveling waves at all the slot locations. In that way, very little energy is wasted and consequently the antenna gain is increased. The feed simplicity and uniplanar configuration of the slot arrays, designed for the frequency range 24.25-27.5 $\mathrm{GHz}$, makes them attractive for radar sensors and high capacity 5G technology applications.
\end{abstract}

Keywords - Antenna array, Symmetrical slot antenna, CPW-fed antenna, Series feeding, CPW T-junction.

\section{INTRODUCTION}

$\mathrm{T}$ HE next $5 \mathrm{G}$ generation of mobile networks aims to allow an ubiquitous connection between hundreds different devices, improving the main properties such as great broadband capacities and transmission speeds [1]. Therefore, new challenges are put to the to design of millimeter band antennas, composed of dozens of radiating elements, whose radiation properties are a crucial property, combined with the reduced size and higher gain [2]. CPW fed slot antennas are considered as good candidates for applications in $5 \mathrm{G}$ mobile communication systems due to their wide bandwidth, low cost, light weight, small size, and

Paper received June 04, 2020; revised April 27, 2021; accepted May 31, 2021. Date of publication July 31, 2021. The associate editor coordinating the review of this manuscript and approving it for publication was Prof. Branko Kolundžija.

This paper is revised and expanded version of the paper presented at the 27th Telecommunications Forum TELFOR 2019 [13].

Marija Milijic is with the Faculty of Electronic Engineering, University of Niš, 18000 Nis, Serbia, (e-mail: marija.milijic@elfak.ni.ac.rs.).

Branka Jokanovic is with the Institute of Physics, University of Belgrade, Pregrevica 118, 11080 Pregrevica, Serbia, and The Academy of Engineering Sciences of Serbia, Kraljice Marije 16, Belgrade, Serbia (e-mail: brankaj@ipb.ac.rs.).

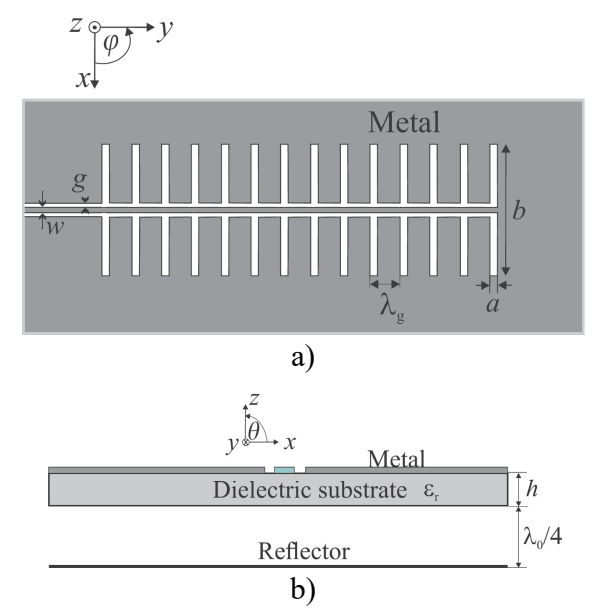

Fig. 1. Linear array of CPW-fed symmetrical slots of rectangular shape: a) top view b) side view.

ease of fabrication and integration with active components [3]-[10].

Compared with previous generations of mobile communication networks, the operation bandwidth of the proposed $5 \mathrm{G}$ networks will be at millimeter - frequencies since it is one of the ways to get rid of the overcrowded sub$6 \mathrm{GHz}$ frequency range. Several promising millimeter-wave bands have been released by International Telecommunication Union (ITU) for the $5 \mathrm{G}$ wireless communication system that include the $24.25-27.5 \mathrm{GHz}$, $37-40.5 \mathrm{GHz}, 66-76 \mathrm{GHz}$ bands [11]. Meanwhile, the Federal Communications Commission (FCC) has considered the spectrum of approximately $11 \mathrm{GHz}$ above $24 \mathrm{GHz}$ for flexible, mobile and fixed wireless broadband for the next-generation $5 \mathrm{G}$ networks and technologies in the United States [12].

This paper presents an extension of the work presented in [13] (the original design) that was shown that the gain of two series fed arrays was significantly higher when two arrays were fed independently, than when the feeding was though the CPW T-junction. Here the advanced design of that array is proposed displaying an enhanced antenna gain as well as better Side Lobe Suppression (SLS) in respect to the design shown in [13].

\section{LinEAR CPW-FED RECTANGULAR SHAPED SLOTS ARRAY}

The configuration of the original linear CPW-fed rectangular slot array [13] is depicted in Fig. 1. It is simulated on a substrate with thickness of $h=0.508 \mathrm{~mm}$ and relative permittivity $\varepsilon_{r}=2.54$. The center frequency $f_{c}=25.875 \mathrm{GHz}$ is calculated as the central value of range 


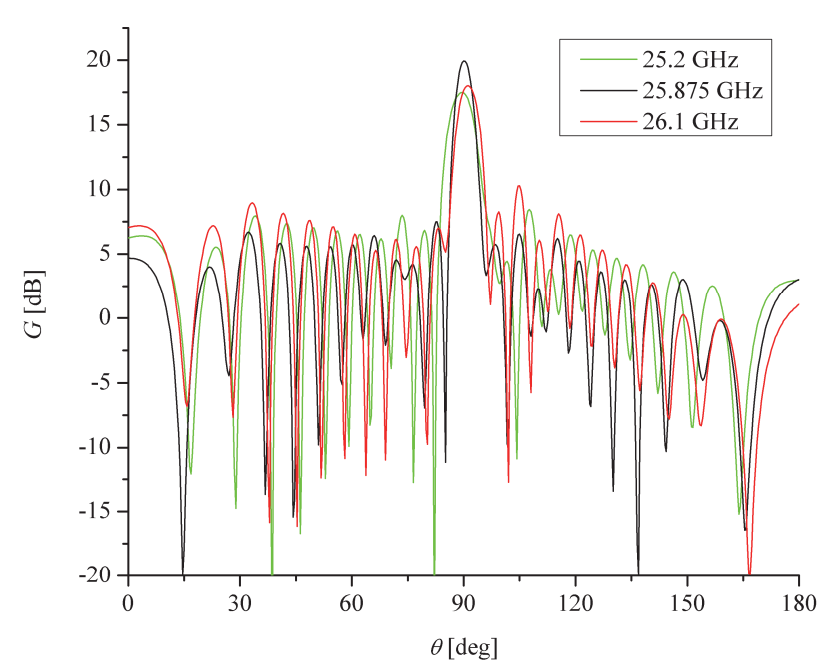

Fig. 2. Radiation pattern in yOz plane $\left(\varphi=90^{\circ}\right)$ of the linear CPW-fed slot array at $25.2 \mathrm{GHz}, 25.875 \mathrm{GHz}$ and $26.1 \mathrm{GHz}$.

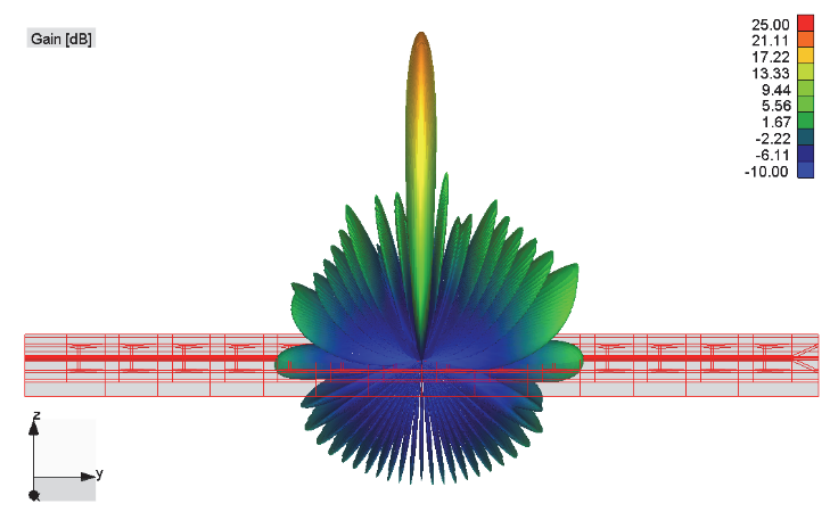

a)

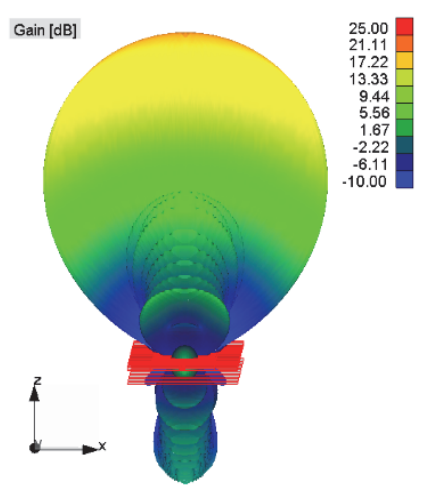

b)

Fig. 3. 3D radiation pattern of the linear CPW-fed symmetrical slot array at the center frequency $f_{c}=25.875 \mathrm{GHz}$ with view of a) yOz plane b) $\mathrm{xOz}$ plane.

$24.25-27.5 \mathrm{GHz}$, recommended by ITU [11]. At the distance $\lambda_{0} / 4=2.89 \mathrm{~mm}$ from the array there is a reflector plate whose dimension are the same as the array's dimensions $\left(\lambda_{0}\right.$ is the wavelength in vacuum at the center frequency $f_{c}=25.875 \mathrm{GHz}$ ). Unlike the microstrip antennas with a backside ground plane, slot antennas require the reflector plane to be at a distance equal to the quarter of the free space wave-length. It should ensure that the antenna radiates only in half the space.

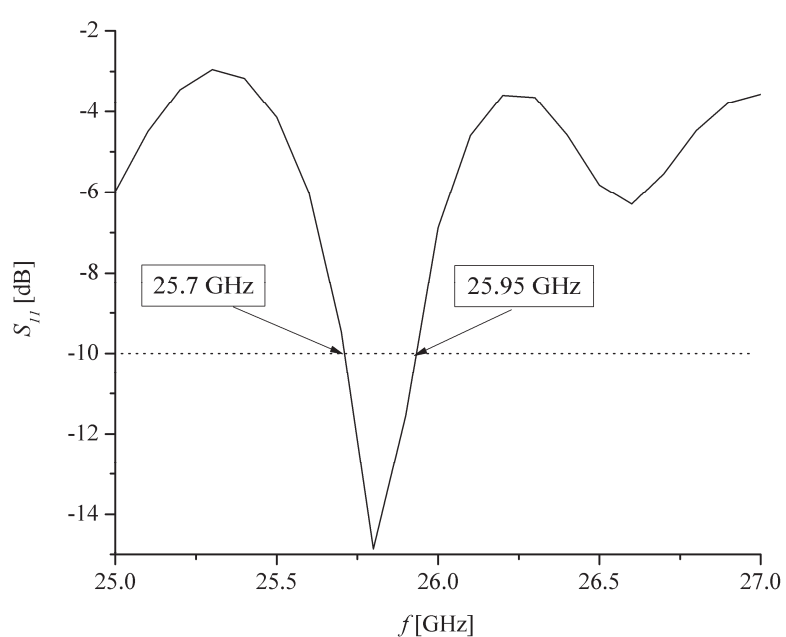

Fig. $4 S_{l l}$ parameter versus frequency of linear CPW-fed slot array. S-parameters are normalized to the $120 \Omega$-impedance of CPW feeding line.

The array is fed by $120 \Omega \mathrm{CPW}$ line featuring the strip $w=0.3 \mathrm{~mm}$ and gap $g=0.375 \mathrm{~mm}$. The dimensions of metal plate are $135 \mathrm{~mm} \times 20 \mathrm{~mm} \times 0.508 \mathrm{~mm}$. The array has 14 slots of a rectangular shape with width $a=0.4 \mathrm{~mm}$ and length $b=10.15 \mathrm{~mm}$. Also, the slots are positioned at mutual distance $d=\lambda_{g}=9 \mathrm{~mm}$, where $\lambda_{g}$ is wavelength of CPW line at the center frequency $f_{c}$.

The radiation patterns for the lower, central and upper frequency are presented in Fig. 2. resulting in the range from $25.2 \mathrm{GHz}$ to $26.1 \mathrm{GHz}$. The maximum gain is about $20 \mathrm{dBi}$ at the central while it drops $2-2.5 \mathrm{~dB}$ at the edge frequencies. SLS is $13 \mathrm{~dB}$ at the central frequency $f_{c}$ when it decreases to $8-9 \mathrm{~dB}$ at the edge frequencies, which is expected for the uniform antenna array.

Moreover, 3D radiation patterns at the center frequency $f_{c}$, obtained by WIPL-D software [14], are displayed in Fig. 3. Its $S_{11}$ parameter versus frequency is depicted in Fig. 4. It can be observed that $S_{11}<-10 \mathrm{~dB}$ for frequencies between $25.7-25.95 \mathrm{GHz}$.

\section{2D CPW-FED ReCtANGUlaR SHAPEd SLOt ARRAY}

The array, shown in Fig. 5, consists of two identical linear 14-slot sub - arrays fed by CPW T-junction with the $60 \Omega$-CPW line (featuring the strip $w_{l}=0.9 \mathrm{~mm}$ and gap $g_{l}=0.1 \mathrm{~mm}$ ) which is used to enable feeding for both sub arrays dividing power into two $120 \Omega \mathrm{CPW}$ feed lines featuring the strip $w_{2}=0.3 \mathrm{~mm}$ and gap $g_{2}=0.375 \mathrm{~mm}$ for feeding every 14 slots sub - array. The dimensions of metal plate are $148 \mathrm{~mm}$ x $30 \mathrm{~mm} \times 0.508 \mathrm{~mm}$. The distance between two sub - arrays is $1.2 \lambda_{0}=14 \mathrm{~mm}$. Slots have width $a=0.4 \mathrm{~mm}$ and length $b=10.15 \mathrm{~mm}$.

In order to test influence of the mutual coupling between slots in $\mathrm{x}$-axis direction, two sub - arrays were firstly investigated when they have independent feeding in the form of two generators for every sub - array (Fig. 6a). Then, the sub - arrays were connected via CPW T - junction (Fig. $6 b)$. The obtained radiation patterns for both considered cases are presented in Figs. 7-10. 


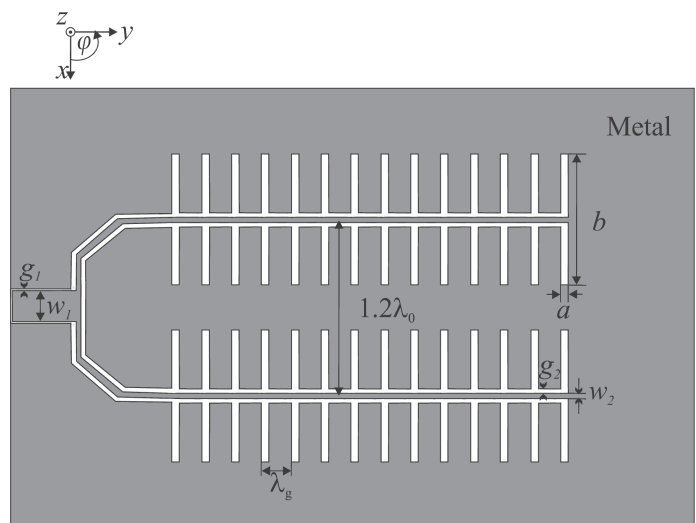

a)

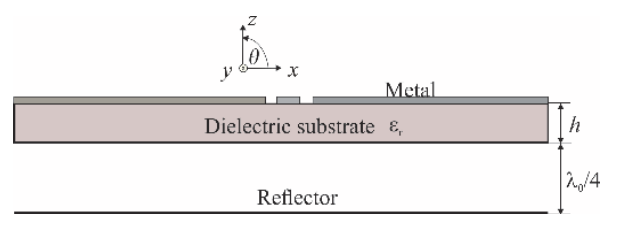

b)

Fig. 5. 2D array of CPW-fed rectangular slots: a) Top view b) Side view.

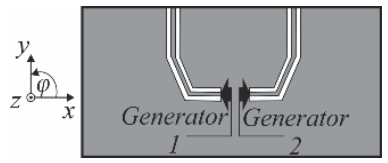

a)

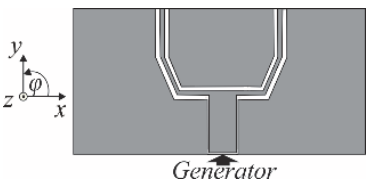

b)
Fig. 6. Feeding for 2D array of rectangular slots by:

a) 2 generators b) CPW T-junction.

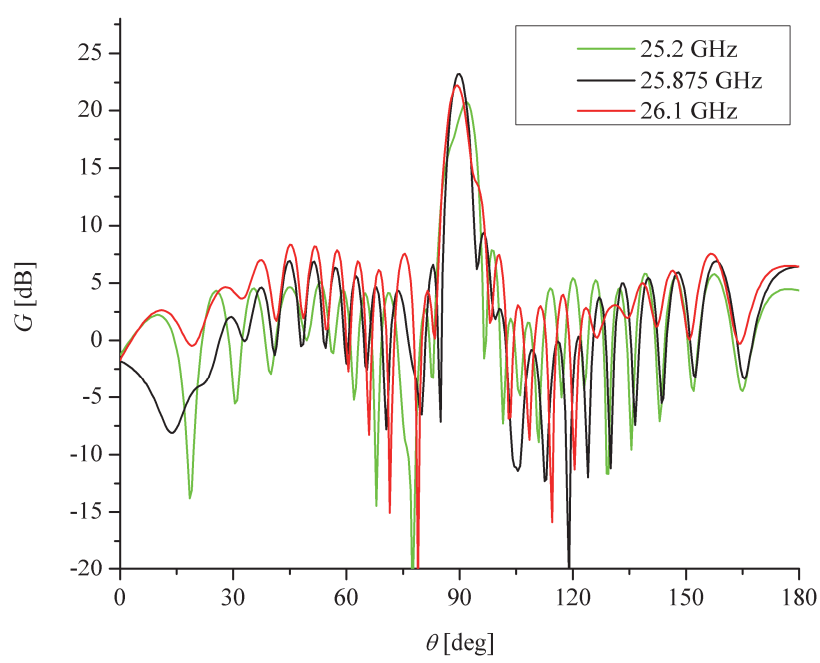

Fig. 7 Radiation pattern in yOz plane $\left(\varphi=90^{\circ}\right)$ of $2 \times 14$ slot array fed by 2 generators at $25.2 \mathrm{GHz}, 25.875 \mathrm{GHz}$ and $26.1 \mathrm{GHz}$.

First considered array, when two generators are used for feeding every sub - array, has a greater gain of about 23.25 $\mathrm{dBi}$ and SLS of $14.5 \mathrm{~dB}$ at the central frequency (Fig. 7). But gain is reduced for $2.5 \mathrm{~dB}$ at the lower $(20.7 \mathrm{dBi})$ and for $1 \mathrm{~dB}$ at higher $(22.25 \mathrm{dBi})$ frequencies. SLS at edge frequencies also decreases. 3D radiation pattern of 2 subarrays of 14 symmetrical slots when two generators are used is shown in Fig. 8. at the central frequency $f_{c}$.

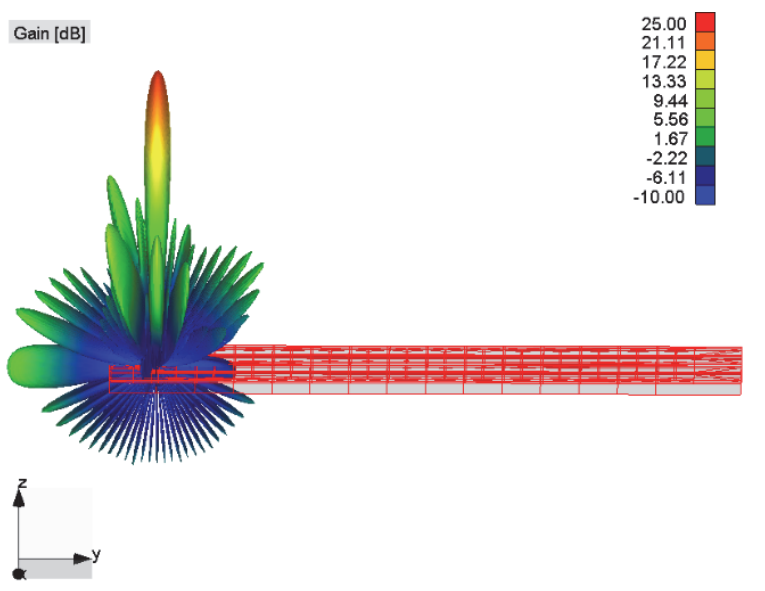

a)

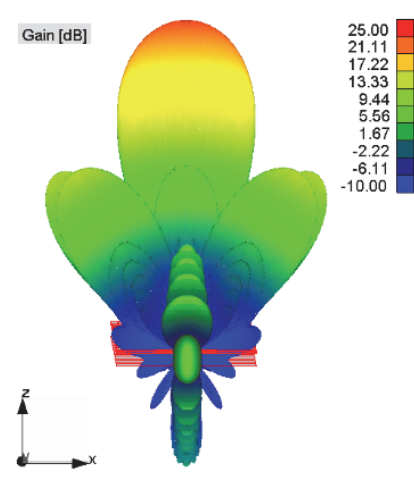

b)

Fig. 83 D radiation pattern of the $2 \times 14$ slot array fed by 2 generators at the center frequency $f_{c}=25.875 \mathrm{GHz}$ with view of a) $\mathrm{yOz}$ plane b) $\mathrm{xOz}$ plane.

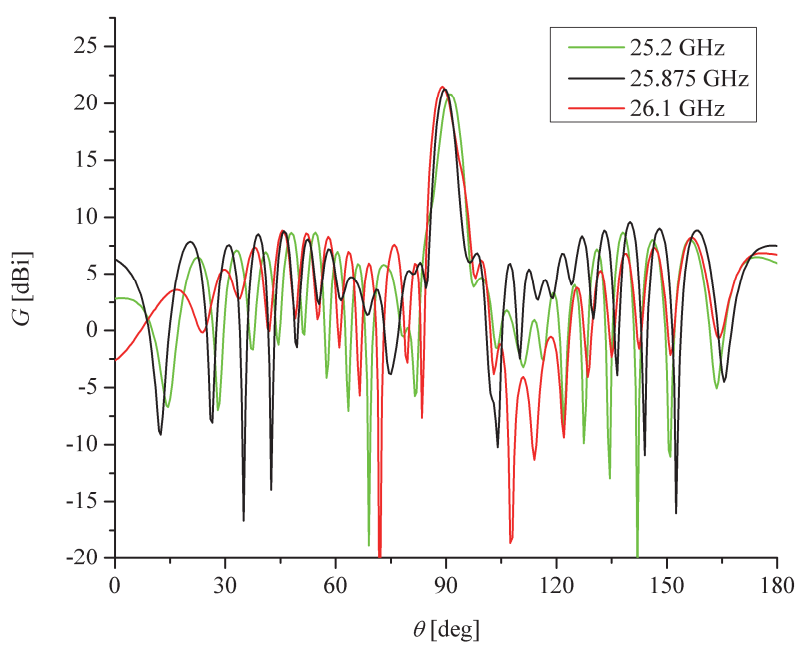

Fig. 9 Radiation pattern in yOz plane $\left(\varphi=90^{\circ}\right)$ of $2 \times 14$ slot array fed by CPW T-junction at $25.2 \mathrm{GHz}, 25.875 \mathrm{GHz}$ and $26.1 \mathrm{GHz}$.

Furthermore, the antenna array of 14 slots sub - arrays that is fed by CPW T-junction has a considerably reduced gain which is about $21 \mathrm{dBi}$ at all three considered frequencies: central, lower and higher (Fig. 9). SLS in this case is about 11-12 dB. The degradation of gain and SLS for the array fed by CPW $\mathrm{T}$ - junction in respect to two separately fed sub -arrays, can be explained by the influence of the power reflected from the adjacent sub - array through the CPW $\mathrm{T}-$ junction. 3D radiation pattern of $2 \times 14$ symmetrical slot array fed by CPW $\mathrm{T}$-junction at central frequency $f_{c}$ is presented in Fig. 10. 


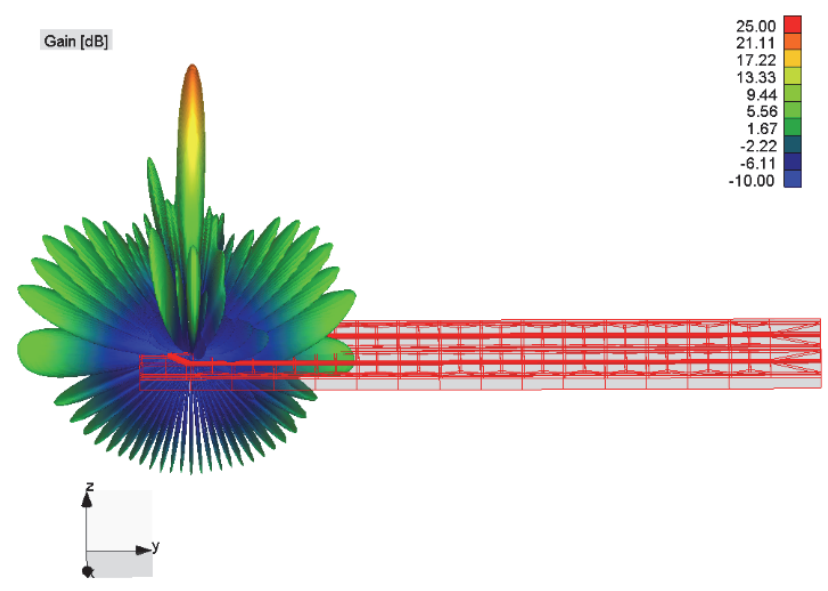

a)

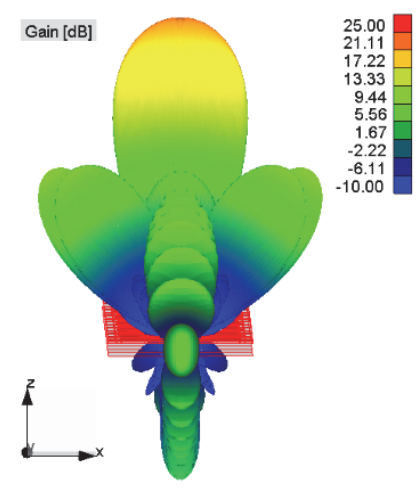

b)

Fig. $103 \mathrm{D}$ radiation pattern of the $2 \times 14$ slot array fed by CPW Tjunction at the center frequency $f_{c}=25.875 \mathrm{GHz}$ with view of a) yOz plane b) $\mathrm{xOz}$ plane.

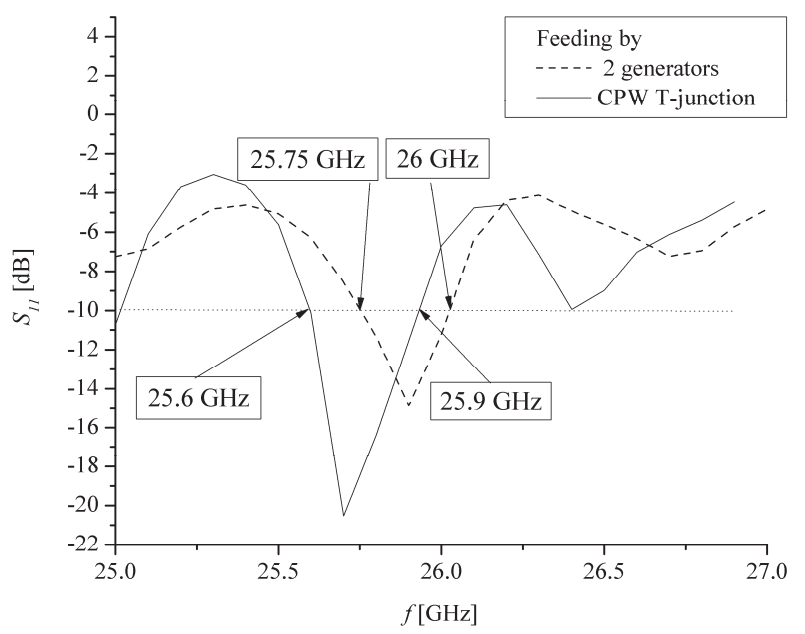

Fig. $11 S_{11}$ parameter versus frequency of $2 \times 14$ slot array for both cases of feeding: fed by 2 generators and fed by CPW T-junction.

The $S_{11}$ parameters of considered antenna array for different cases of feeding are presented in Fig. 11. When two generators feed every sub - array, $S_{11}$ is normalized to the impedance of CPW feeding line $(120 \Omega)$ and it is less than $-10 \mathrm{~dB}$ for range between $25.75-26 \mathrm{GHz}$ (dash line). This result corresponds with $S_{11}$ parameter of the linear CPW-fed slot array from Fig. 4. which confirms that the mutual coupling between slots in the $\mathrm{x}$-axis direction (Fig. 5.) is not considerably expressed. Furthermore, when the antenna array is fed by CPW T-junction, S-parameters

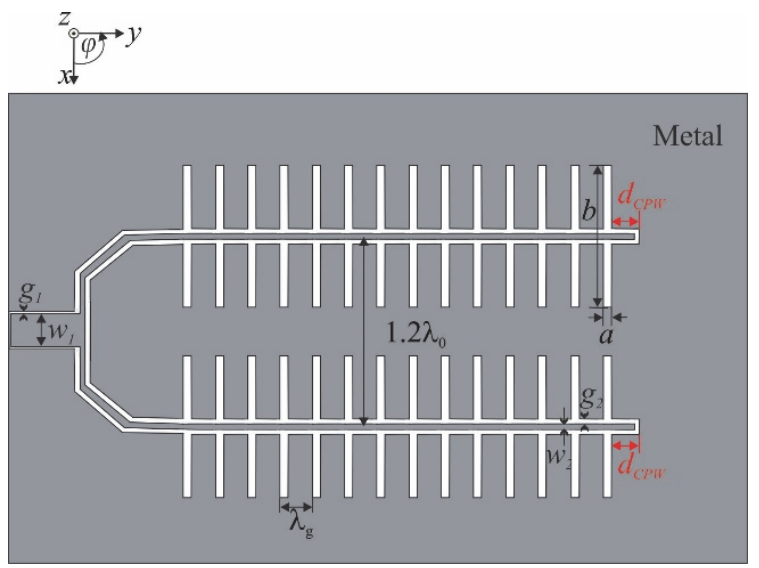

Fig. 12. Top view of advanced design of 2D array of CPW-fed rectangular shaped slots.

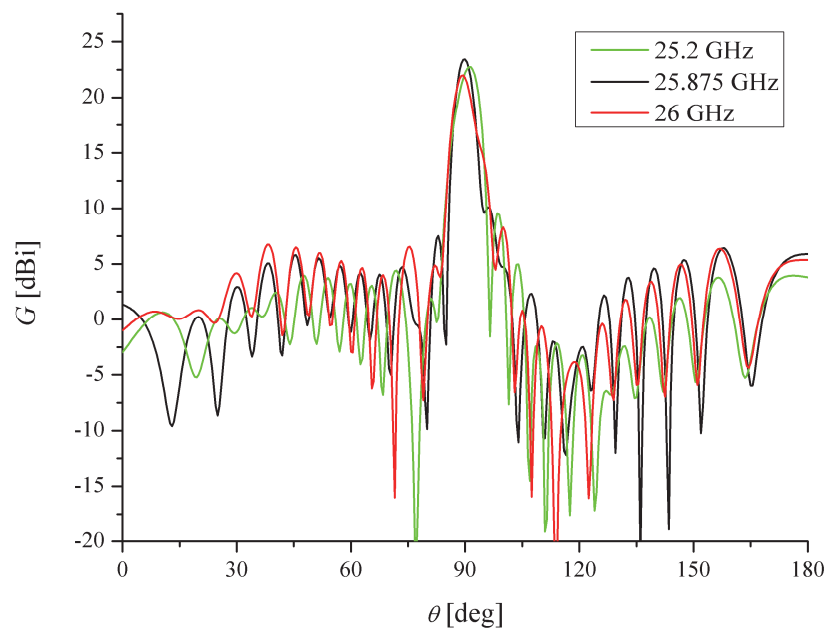

Fig. 13 Radiation pattern in yOz plane $\left(\varphi=90^{\circ}\right)$ of advanced design of 2 x 14 slot array fed by 2 generators at $25.2 \mathrm{GHz}, 25.875$ $\mathrm{GHz}$ and $26 \mathrm{GHz}$.

are normalized to the impedance of CPW feeding line with width $w_{l}$ and gap $g_{l}(60 \Omega)$. Considering presented results in Fig. 11, the bandwidth of antenna array fed by CPW-T junction (solid line) respecting $S_{11}<-10 \mathrm{~dB}$ does not vary a bit from bandwidth of previously investigated antenna array.

\section{AdVANCED DESIGN OF 2D CPW-FED RECTANGULAR SLOT ARRAY}

The results from the previous section demonstrate that gain significantly decreases when the antenna array is fed by CPW-T junction [13]. The advanced design of the proposed slot array is presented in Fig. 12. Both antenna sub-arrays have additional open-circuited stub that is the extension of the CPW feeding line after the last slot for the length $d_{C P W}$. The value $d_{C P W}=7.1 \mathrm{~mm}$ is optimized in order to obtain the best possible gain in the considered frequency range. In that way the energy remaining after the last array element is reflected back from the stub and re-radiated through the slot arrays. The length of the stub is optimized to provide that the reflected wave is in phase with the forward-traveling waves at all the slot locations. It provides that very little energy is wasted and consequently the antenna gain is increased. 


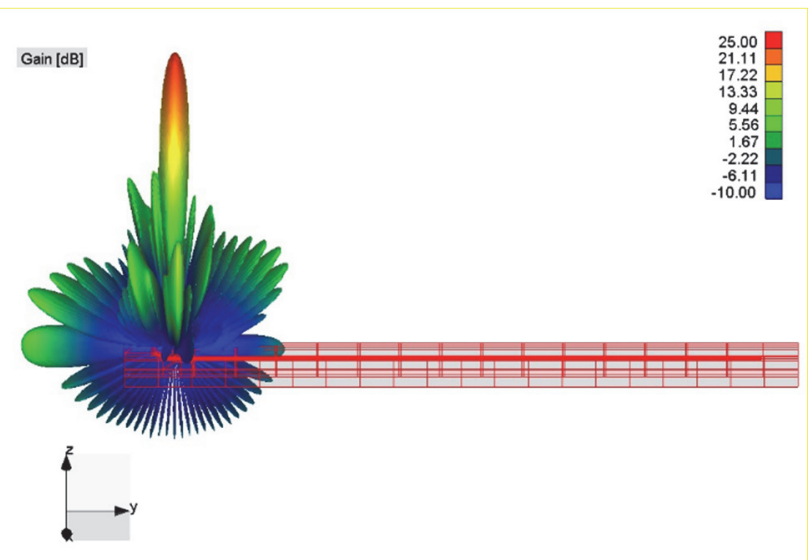

a)

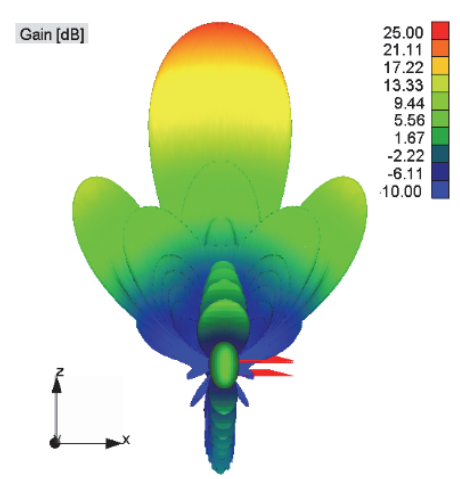

b)

Fig. 14 3D radiation pattern of the advanced design of $2 \times 14$ slot array fed by 2 generators at the center frequency $f_{c}=25.875 \mathrm{GHz}$ with view of a) $\mathrm{yOz}$ plane b) $\mathrm{xOz}$ plane.

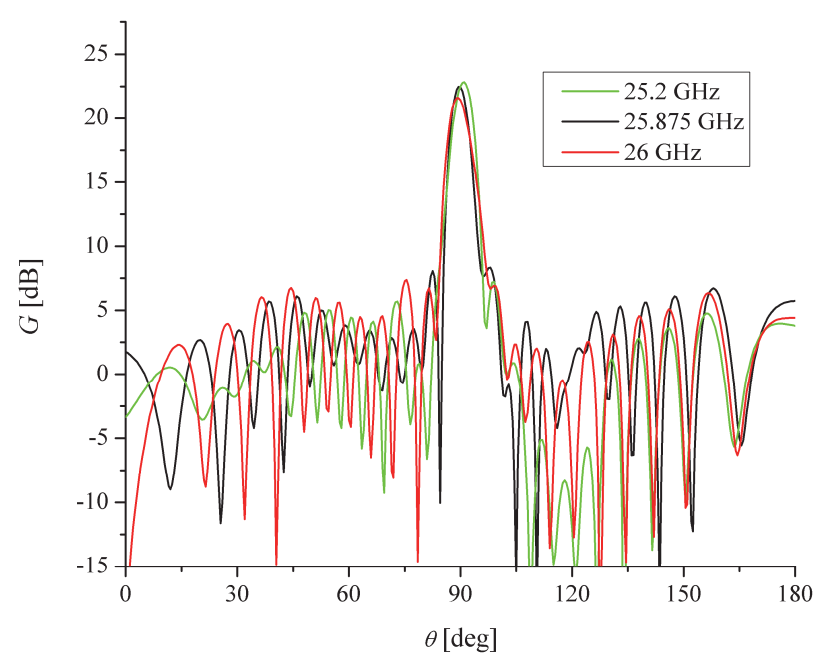

Fig. 15 Radiation pattern in yOz plane $\left(\varphi=90^{\circ}\right)$ of advanced design of 2x14 slot array fed by CPW T-junction at $25.2 \mathrm{GHz}$, $25.875 \mathrm{GHz}$ and $26 \mathrm{GHz}$.

Firstly, the proposed advanced design is fed by two independent generators for every sub-array. The corresponding $2 \mathrm{D}$ and $3 \mathrm{D}$ radiation patterns are presented in Fig. 13-14. It can be concluded that gain is $23.4 \mathrm{dBi}$ at the center frequency, $22.7 \mathrm{dBi}$ at lower frequency and $22 \mathrm{dBi}$ at upper frequency. Similarly, SLS is $13.5 \mathrm{~dB}$ at the center frequency and at lower frequency, while it increases to $14 \mathrm{~dB}$ at upper frequency.

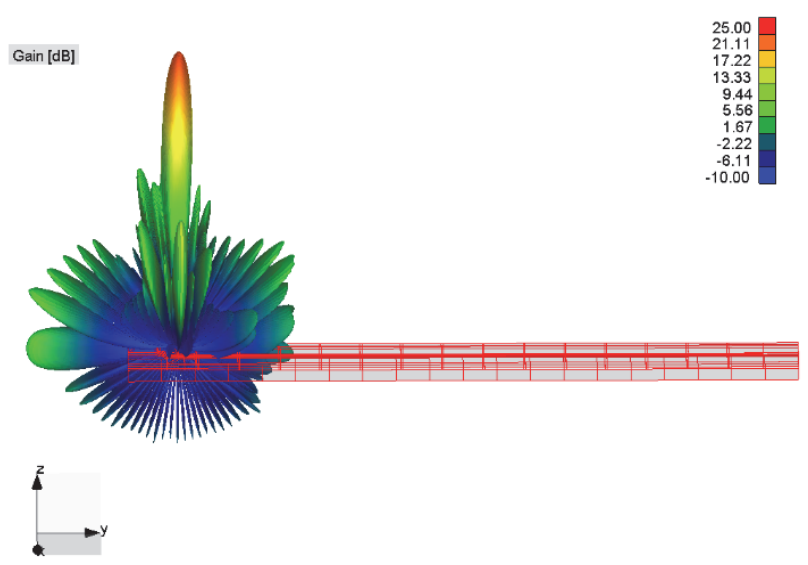

a)

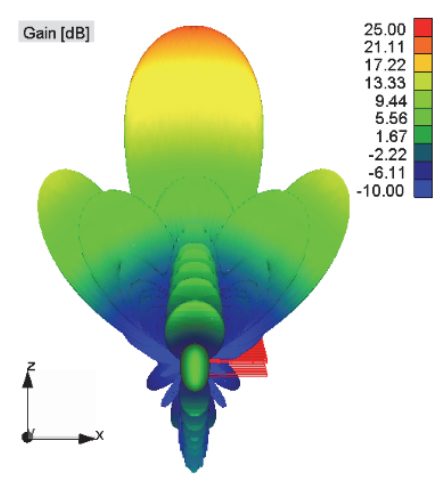

b)

Fig. $163 \mathrm{D}$ radiation pattern of the advanced design of $2 \times 14$ slot array fed by CPW T-junction at the center frequency

$f_{c}=25.875 \mathrm{GHz}$ with view of a) $\mathrm{yOz}$ plane b) $\mathrm{xOz}$ plane.

Similarly, like original antenna array, the gain of antenna array fed by CPW-T junction decreases. Although in the case of advanced design, this change is very small (less than $1 \mathrm{~dB}$ ). The 2D and 3D radiation patterns of the advanced design of $2 \times 14$ symmetrical slot array fed by CPW Tjunction are shown in Figs. 15-16. The gain is $22.5 \mathrm{dBi}$ and SLS is $14.3 \mathrm{~dB}$ at the center frequency $f_{c}$. The gain does not change at lower frequency but it falls at the upper frequency to value $21.6 \mathrm{dBi}$. SLS is 15.5 at lower frequency and $14.3 \mathrm{~dB}$ at upper frequency. However, the gain of the proposed advanced design of slot array fed by CPW Tjunction is higher the gain of the original design for $1.5-2 \mathrm{~dB}$ in the considered frequency range.

The Fig. 17. and the Table 1 - 3 gives the comparison between the main parameters of the original and advanced design of $2 \times 14$ symmetrical slot arrays through the design stages. Considering presented results, it can be concluded that advanced design of the proposed slot array has better radiation characteristics when open-circuited stub is added at the end of each sub - array. Therefore, the extension of CPW feeding line of both sub-arrays increases the antenna gain by reflecting the remaining energy after the last radiating slot in phase with the forward-traveling waves. The difference in the value of the gain between two ways of feeding the antenna array was a good indicator that the design needs to be improved. 


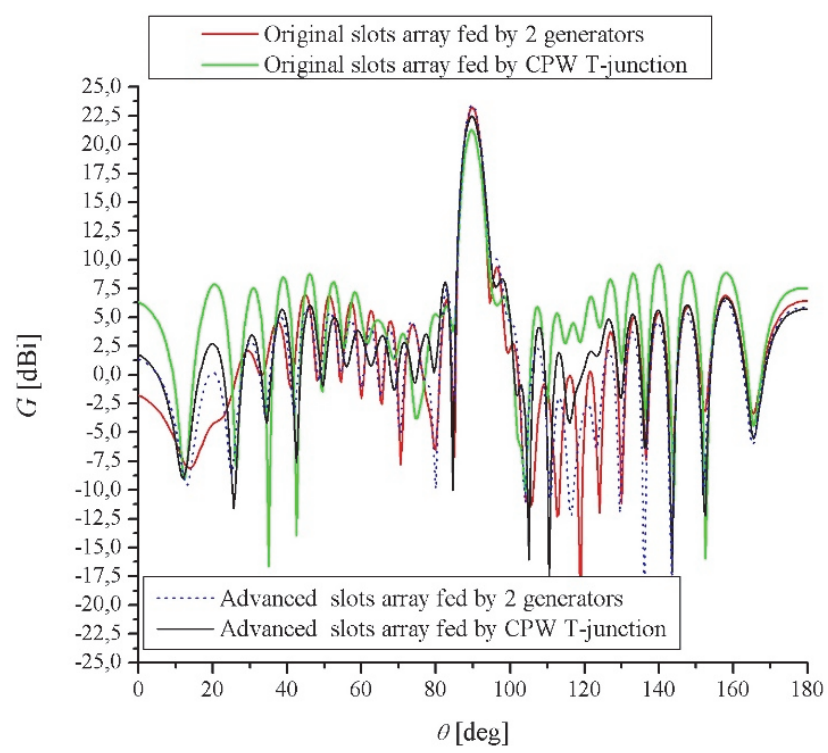

Fig. 17 Radiation pattern in yOz plane $\left(\varphi=90^{\circ}\right)$ of $2 \times 14$ slot array through the design stages at $25.875 \mathrm{GHz}$ for both original and advanced design.

TABLE 1: MAIN CHARACTERISTICS OF THE ORIGINAL AND ADVANCED SLOT ARRAYS OF 2 X14 ELEMENTS AT CENTER FREQUENCY $f_{c}=25.875 \mathrm{GHz}$

\begin{tabular}{|l|c|c|c|c|}
\hline$f_{c}=25.875 \mathrm{GHz}$ & \multicolumn{2}{|c|}{ Original design } & \multicolumn{2}{c|}{ Advanced design } \\
\hline Feeding & $\begin{array}{c}2 \\
\text { generators }\end{array}$ & $\begin{array}{c}\text { CPW }-\mathrm{T} \\
\text { junction }\end{array}$ & $\begin{array}{c}2 \\
\text { generators }\end{array}$ & $\begin{array}{c}\text { CPW }-\mathrm{T} \\
\text { junction }\end{array}$ \\
\hline Gain $[\mathrm{dBi}]$ & $\mathbf{2 3 . 2 5}$ & $\mathbf{2 1}$ & $\mathbf{2 3 . 4}$ & $\mathbf{2 2 . 5}$ \\
\hline SLS [dB] & 14.5 & 12 & 13.5 & 14.3 \\
\hline Bandwidth & $25.2-$ & $25.2-$ & $25.2-26$ & $25.2-26$ \\
[GHz] & 26.1 & 26.1 & & \\
\hline
\end{tabular}

TABLE 2: MAIN CHARACTERISTICS OF THE ORIGINAL AND ADVANCED SLOT ARRAYS OF 2X14 ELEMENTS AT THE LOWER EDGE FREQUENCY $f_{\text {lef }}$

\begin{tabular}{|l|c|c|c|c|}
\hline$f_{\text {lef }}$ & \multicolumn{2}{|c|}{ Original design } & \multicolumn{2}{c|}{ Advanced design } \\
\hline Feeding & $\begin{array}{c}2 \\
\text { generators }\end{array}$ & $\begin{array}{c}\text { CPW }-\mathrm{T} \\
\text { junction }\end{array}$ & $\begin{array}{c}2 \\
\text { generators }\end{array}$ & $\begin{array}{c}\text { CPW-T } \\
\text { junction }\end{array}$ \\
\hline Gain $[\mathrm{dBi}]$ & $\mathbf{2 0 . 7}$ & $\mathbf{2 0 . 8}$ & $\mathbf{2 2 . 7}$ & $\mathbf{2 2 . 8}$ \\
\hline SLS $[\mathrm{dB}]$ & 13 & 12 & 13.5 & 15.5 \\
\hline
\end{tabular}

TABLE 3: MAIN CHARACTERISTICS OF THE ORIGINAL AND ADVANCED SLOT ARRAYS OF 2 X14 ELEMENTS AT THE UPPER EDGE FREQUENCY $f_{\text {uef }}$

\begin{tabular}{|l|c|c|c|c|}
\hline$f_{\text {uef }}$ & \multicolumn{2}{|c|}{ Original design } & \multicolumn{2}{c|}{ Advanced design } \\
\hline Feeding & $\begin{array}{c}2 \\
\text { generators }\end{array}$ & $\begin{array}{c}\text { CPW }-\mathrm{T} \\
\text { junction }\end{array}$ & $\begin{array}{c}2 \\
\text { generators }\end{array}$ & $\begin{array}{c}\text { CPW -T } \\
\text { junction }\end{array}$ \\
\hline Gain $[\mathrm{dBi}]$ & $\mathbf{2 2 . 2 5}$ & $\mathbf{2 1 . 6}$ & $\mathbf{2 2}$ & $\mathbf{2 1 . 6}$ \\
\hline SLS $[\mathrm{dB}]$ & 14 & 13.5 & 14 & 14.3 \\
\hline
\end{tabular}

\section{CONCLUSION}

Antenna design is one of the major considerations to realize mm-wave based 5G mobile networks. Modern wireless communication system requires low profile, light weight, high gain and ease of installation, antenna systems. The design of a wideband compact antenna is a challenging task especially at higher frequencies around $28-\mathrm{GHz}$.

A high-gain coplanar waveguide-fed slot antenna array is presented in this letter. The antenna consists of two identical sub - arrays of 14 symmetrical slots. Two types of excitation are considered. Firstly, two independent generators were employed to feed each sub - array in order to investigate antenna parameters without influence of the $\mathrm{CPW} \mathrm{T}$ - junction. Afterwards, the $\mathrm{CPW} \mathrm{T}-$ junction was used to excite the array. Presented results of radiation pattern show that CPW $\mathrm{T}$ - junction affects antenna radiation pattern (its gain and SLS). Therefore, the advance design of proposed slot array is presented in this paper. CPW feeding line of both sub-arrays is extended after the last slot in order to get a better radiation characteristic. Presented results show that the advanced design of $2 \times 14$ symmetrical slot array provides higher gain for $1.5 \mathrm{~dB}$ and SLS for $2 \mathrm{~dB}$ in respect to the original design when feeding is done via CPW-T junction. Its main disadvantage is a bit smaller bandwidth which is less for $100 \mathrm{MHz}$ then the bandwidth of the original design of proposed slot array.

\section{REFERENCES}

[1] V. Milosevic, B. Jokanovic, O. Boric-Lubecke, V. M. Lubecke, "Key Microwave and Millimeter Wave Technologies for 5G Radio," in Powering the Internet of Things with $5 G$ Networks, V. Mohanan, R. Budiatru, I. Aldmour, Eds. IGI Global, July 2017, DOI: 10.4018/9781-5225-2799-2.

[2] B. Jokanovic, V. Milosevic, M. Radovanovic N. Boskovic, "Advanced antennas for next generation wireless access," 2017 13th International Conference on Advanced Technologies, Systems and Services in Telecommunications (TELSIKS), Nis, 2017, pp. 87-94.

[3] G. H. Elzwawi, M. Mantash and T. A. Denidni, "Improving the gain and directivity of CPW antenna by using a novel AMC surface," 2017 IEEE International Symposium on Antennas and Propagation, San Diego, CA, 2017, pp. 2651-2652.

[4] M. Milijic, B. Jokanovic, "Radiation bandwidth of series-fed slot arrays for 5G and IoT applications," 2018 26th Telecommunications Forum (TELFOR), Belgrade, Serbia, Nov. 2018,pp. 462-465,

[5] W. Tu, "Analysis and Design of Coplanar Waveguide-Fed Capacitively Coupled Slot Antennas", 2015 International Workshop on Antenna Technology, Seoul, Republic of Korea, 4-6 March 2015.

[6] M. Yang, X. Yin, H. Zhao, "Wideband Coplanar Waveguide-Fed Slot Antenna Array with Via-Wall Structure," Proc. of 2016 10th European Conference on Antennas and Propagation, Davos, Switzerland, 10-15 April 2016.

[7] P. Chaudhary, A. Kumar and R. Mittra, "Quadrilateral-Shaped Wideband Circularly Polarized CPW-Fed Monopole Antenna," 2019 URSI Asia-Pacific Radio Science Conference (AP-RASC), New Delhi, India, 2019, pp. 1-4.

[8] M. E. de Cos Gómez, H. Fernández Álvarez, C. García González, B. Puerto Valcarce, J. Olenick and F. Las-Heras, "Ultra-Thin Compact Flexible Antenna for IoT Applications," 2019 13th European Conference on Antennas and Propagation (EuCAP), Krakow, Poland, 2019, pp. 1-4.

[9] A. I. Afifi, D. M. Elsheakh, A. B. Abdel-Rahman, A. Allam and S. M. Ahmed, "Dual Broadband Coplanar Waveguide-Fed Slot Antenna for 5G Applications," 2019 13th European Conference on Antennas and Propagation (EuCAP), Krakow, Poland, 2019, pp. 1-3.

[10] A. Zaidi, A. Baghdad, W. A. Awan, Halima, A. Ballouk and A. Badri, "CPW Fed Wide to Dual Band Frequency Reconfigurable Antenna for 5G Applications," 2019 International Conference on Wireless Technologies, Embedded and Intelligent Systems (WITS), Fez, Morocco, 2019, pp. 1-3.

[11] W. Hong, K. Baek, S. Ko "Millimeter-Wave 5G Antennas for Smartphones: Overview and Experimental Demonstration," IEEE Trans. Antennas Propag., December 2017, vol. 65, no. 12, pp. 6250 $-6261$.

[12] M. J. Marcus, 5G and "IMT for 2020 and beyond," IEEE Wireless Commun., Aug. 2015, vol. 22, no. 4, pp. 2-3.

[13] M. Milijić, B. Jokanović, "High-gain Slot Antenna Arrays for 5G and Radar Applications," 2019 27th Telecommunications Forum (TELFOR), Belgrade, Serbia, Nov. 2019, pp. 381-384.

[14] WIPL-D Pro, WIPL-D Team. 